\title{
0 Seguro Depósito Induz ao Risco Moral nas Cooperativas de Crédito Brasileiras? Um Estudo com Dados em Painel*
}

\author{
Valéria Gama Fully Bressan ${ }^{\dagger}$, Marcelo José Braga ${ }^{\ddagger}$, Aureliano Angel \\ Bressan $^{\S}$, Moisés de Andrade Resende-Filho
}

\footnotetext{
Contents: 1. Introdução; 2. Revisão da Literatura sobre Seguro Depósito e Moral Hazard; 3. Metodologia; 4. Resultados e Discussão; 5. Conclusões.

Keywords: Risco Moral; Seguro Depósito, Cooperativas de Crédito, Índice de Basileia, Dados em Painel.

JEL Code: G21, D82, C23.
}

Interesses conflitantes e monitoramento imperfeito podem induzir instituições financeiras cobertas por seguro depósito a se exporem mais ao risco do que o nível preconizado pelo fundo gestor do seguro. Testa-se se a instauração do Fundo Garantidor (FGS) do Sistema das Cooperativas de Crédito do Brasil (Sicoob) não induziu ao problema de risco moral. Utiliza-se um painel com dados mensais de 180 cooperativas (61,43\% das cooperativas filiadas ao Sicoob). Modelos de dados em painel estimados com o índice de Basileia como proxy da exposição ao risco das cooperativas indicam que a instauração do FGS induziu ao problema de risco moral.

Conflicting interests and imperfect monitoring can induce financial institutions covered by the deposit insurance to run into more risk than the level aimed by its fund administrator. We test if the establishment of the deposit insurance (FGS) of the Brazilian Cooperative Credit System (Sicoob) did not induce moral hazard. We use a panel composed of monthly data for 180 credit unions (61.43\% of cooperatives affiliated to Sicoob). Panel data models' estimates using the Basel index as proxy for the risk exposure of cooperatives indicate that the FGS induced the moral hazard problem.

\footnotetext{
* Os autores agradecem o financiamento concedido pelo CNPq para a realização da pesquisa.

†Departamento de Ciências Contábeis, Centro de Pós-Graduação e Pesquisas em Contabilidade e Controladoria, Faculdade de Ciências Econômicas, Universidade Federal de Minas Gerais (UFMG). E-mail: vfully@face .ufmg.br

${ }^{\ddagger}$ Departamento de Economia Rural, Universidade Federal de Viçosa (UFV). E-mail: mjbraga@uf v . br

$\S$ Centro de Pós-Graduação e Pesquisa em Administração, Faculdade de Ciências Econômicas, Universidade Federal de Minas Gerais (UFMG). E-mail: aureliano@ufmg.br

I Departamento de Economia, Universidade de Brasília (UnB). E-mail: moisesresende@unb.br
} 


\section{INTRODUÇÃO}

O seguro depósito é um instrumento que, em caso de falência de uma instituição financeira depositária, garante que seja honrada a totalidade ou uma fração pré-estabelecida do principal e juros acumulados em contas protegidas pelo seguro. O primeiro país a instituir um sistema nacional de seguro depósito (Federal Deposit Insurance Corporation - FDIC) foi os EUA em 1933, em meio à crise bancária, com os objetivos de restaurar a confiança (Alston et al., 1994) e liquidez do seu sistema bancário e proteger os pequenos investidores (Baltagi, 2005) apud (Demirgüç-Kunt and Kane, 2002). Apesar disso, antes mesmo de 1933, especificamente entre 1909 e os anos 1920, oito Estados dos EUA já haviam instaurado independentemente programas de seguro depósito. Além disso, a lei da moeda nacional (the National Currency Act) de 1863, que criava a base para o sistema nacional bancário dos EUA, já previa a explícita garantia do Tesouro dos EUA das notas emitidas pelos bancos nacionais (Weber, 2010).

A primeira experiência com seguro depósito no Brasil se deu com a instauração do Fundo Garantidor de Crédito (FGC) do sistema bancário brasileiro em 1995. O FGC foi criado como uma entidade privada, sem fins lucrativos, destinada a administrar o sistema de seguro depósito para a proteção de titulares de créditos em instituições financeiras, exceto as cooperativas de crédito e as seções de crédito das cooperativas.

Confirmado o padrão sugerido por Hannafin and McKillop (2007), seguindo o exemplo do FGC do sistema bancário brasileiro, o Fundo Garantidor do Sicoob (FGS) foi instaurado em 2005 pelo Sistema das Cooperativas de Crédito do Brasil (Sicoob).

O Sicoob ${ }^{1}$ atua em 21 Estados brasileiros e no Distrito Federal disponibilizando produtos e serviços financeiros, é composto por 14 cooperativas centrais, 584 cooperativas singulares ${ }^{2}$ de crédito, possui 1.884 postos de atendimento cooperativo (PACs) e conta com a participação de mais de 1,9 milhão de associados e pela Confederação Nacional de Cooperativas de Crédito ou Sicoob-Brasil. Em 2010, o Sicoob possuía R 14.033 milhões em operações de crédito, R\$ 13.738 milhões em depósitos, R\$ 6.146 milhões em patrimônio líquido, R\$ 667 milhões de resultado anual e R\$24,716 milhões de ativos totais (SICOOB, 2012). Apesar de as cooperativas brasileiras de crédito estarem organizadas nos sistemas Sicoob, Sicredi, Unicred, Ancosol, Cooperativas Independentes e outros, o Sicoob é o maior sistema de cooperativas de crédito do Brasil, pois congrega $46,32 \%$ das cooperativas singulares de crédito brasileiras (Soares and de Melo Sobrinho, 2007).

Os modelos que tratam do efeito da instauração de um seguro depósito pelo governo sobre potenciais crises do setor financeiro, segundo Sargent (2010) possuem dois extremos. Em um dos extremos, um seguro depósito financiado pelo governo é visto como algo absolutamente bom (vide o trabalho seminal de Bryant (1980) e a sua extensão por Diamond and Dybvig (1983)), pois ao fazer com que os investidores acreditem que os seus investimentos estão absolutamente a salvo, elimina por completo a vulnerabilidade da economia a potenciais corridas aos bancos. Melhor ainda, no final das contas, não custará absolutamente nada ao governo bancar esse seguro depósito. No extremo oposto, o seguro depósito é visto como algo absolutamente ruim. Para tanto o trabalho seminal de Kareken and Wallace (1978) é categórico ao demonstrar que um governo estará criando as condições para uma crise financeira se instaurar um seguro depósito e, ao mesmo tempo, não regular os bancos no sentindo de evitar que assumam riscos excessivos. Segundo Sargent (2010), no mundo real o formulador de política deve se preocupar tanto com a possibilidade de corrida aos bancos como com o problema de risco moral.

\footnotetext{
${ }^{1}$ As cooperativas filiadas ao Sicoob são cooperativas de perfil vertical, pois apresentam estrutura piramidal onde cooperativas singulares ficam na base, cooperativas centrais estão na zona intermediária e confederações estão no topo da pirâmide. Note que cooperativas centrais, federações de cooperativas ou cooperativas de segundo grau são aquelas constituídas por pelo menos três cooperativas singulares.

${ }^{2}$ As cooperativas singulares ou de primeiro grau são aquelas constituídas por pelo menos vinte pessoas físicas.
} 
De fato, um seguro depósito, quando inadequadamente desenhado, pode acabar aumentando a instabilidade do sistema financeiro na medida em que, reduzindo o risco das operações correntes das instituições financeiras, abre espaço para que elas se envolvam em operações excessivamente arriscadas. Na verdade, os interesses conflitantes ${ }^{3}$ das partes e a inviabilidade de se monitorar ou observar as ações das instituições financeiras torna inviável o desenho de contratos fundamentados no nível de exposição ao risco dessas instituições. Com isso, cada instituição financeira, no melhor do seu interesse, poderá se expor mais ao risco do que o nível preconizado pelo fundo garantidor do seguro depósito sem que tal comportamento possa ser detectado (problema de risco moral). Com isso, a instauração de um sistema de seguro depósito por um setor, ao induzir ao problema de risco moral, pode terminar ocasionando maior instabilidade financeira para si e, por conseguinte, para todo o sistema financeiro (Clair, 1984).

Hannafin and McKillop (2007) reconhecem que a instauração de um sistema de seguro depósito pelo setor de cooperativas de crédito pode induzi-lo ao problema de risco moral. Isso porque a instauração do seguro depósito pode induzir cooperativas de crédito a se exporem mais ao risco do que o nível preconizado pelo fundo garantidor do seguro depósito.

Estudos que testam empiricamente a hipótese de que a instauração de um sistema de seguro depósito não induz ao problema do risco moral, têm obtido resultados conflitantes. Por exemplo, Black and Dugger (1981) e Clair (1984) encontraram evidências de que, após a instauração de seguro depósito, as cooperativas de crédito americanas passaram a assumir maiores riscos, o que interpretam como um indicativo favorável a hipótese de indução do problema de risco moral. Resultados opostos foram obtidos por Kane and Hendershott (1996) e Hannafin and McKillop (2007).

Fischer and Fournier (2002) demonstraram que o seguro depósito induz cooperativas de crédito ao problema de risco moral e que cooperativas dominadas por membros tomadores de recursos se expõem mais ao risco do que aquelas dominadas por membros aplicadores de recursos. Por outro lado, Karels and McClatchey (1999) avaliaram as cooperativas de crédito americanas no período de 1970 a 1977 e não encontraram evidências de que a adoção do seguro depósito estimulou o comportamento pró-risco destas cooperativas.

Dado os resultados conflitantes da literatura, o efeito da instauração de seguro depósito sobre o nível de risco assumido por cooperativas de crédito é uma questão ainda em aberto. Com isso, o presente trabalho utiliza o caso da instauração do Fundo Garantidor do Sicoob (FGS) em 2005 para testar a hipótese de que a instauração do seguro não induz ao problema de risco moral no caso das cooperativas de crédito brasileiras. ${ }^{4}$ Note que a implicação direta da rejeição dessa hipótese é que a instauração do FGS aumentou a instabilidade do sistema de cooperativismo de crédito brasileiro e, por conseguinte, de todo o sistema financeiro nacional. Dessa forma, os resultados obtidos no presente estudo podem servir para subsidiar a revisão e criação de normas e decisões do Conselho Monetário Nacional e do Banco Central do Brasil.

O presente estudo é, no melhor do nosso conhecimento, o primeiro a avaliar o problema de risco moral potencialmente gerado com a instauração de um sistema de seguro depósito pelas cooperativas de crédito brasileiras. Para tanto, utilizamos o índice de Basileia como proxy para o grau de exposição ao risco das cooperativas de crédito em nossa amostra. Optamos por utilizar esse índice por ele ser

\footnotetext{
${ }^{3}$ Por exemplo, o fundo garantidor do seguro depósito visa à estabilidade do setor enquanto cada instituição financeira visa maximizar o seu próprio lucro.

${ }^{4}$ As cooperativas de crédito são classificadas pelo Sistema Financeiro Nacional dentro do grupo das instituições financeiras captadoras de depósitos à vista, o que as torna objeto de normatização pelo Conselho Monetário Nacional e de supervisão pelo Banco Central do Brasil. Portanto, reconhecemos que já há um problema de risco moral entre as cooperativas de crédito e o Banco Central que as monitora, antes mesmo da criação do FGS do Sicoob. O problema de risco moral investigado no presente artigo diz respeito às transações entre o FGS do Sicoob e as suas cooperativas integrantes, transações essas que não poderiam existir antes da criação desse sistema de seguro depósito.
} 
oriundo do Acordo da Basileia ${ }^{5}$ que surgiu em decorrência dos desafios da regulamentação bancária, da contabilização e do crescente fluxo financeiro que demandaram um arcabouço regulatório internacional bancário (BANCO CENTRAL DO BRASIL, 2006).

$\mathrm{O}$ artigo está estruturado da seguinte forma. A Seção 2 apresenta uma revisão da literatura sobre estudos que tratam da relação entre o seguro depósito e risco moral em cooperativas de crédito. Essa revisão da literatura será a base para a especificação dos modelos econométricos do nosso estudo. A Seção 3 apresenta o modelo analítico e a Seção 4 descreve a amostra e a fonte dos dados. A Seção 5 discute os resultados obtidos e a Seção 6 apresenta nossas Considerações Finais.

\section{REVISÃO DA LITERATURA SOBRE SEGURO DEPÓSITO E MORAL HAZARD}

O propósito desta seção de revisão é demonstrar a ausência de consenso sobre o efeito da instauração de seguro depósito sobre o problema de risco moral, e apresentar de forma sistemática os estudos sobre esta temática, discriminado os trabalhos referentes a cooperativas e os referentes a bancos.

Um dos primeiros trabalhos a examinar o efeito da instauração de um seguro depósito sobre a criação do problema de risco moral em cooperativas de crédito foi desenvolvido por Clair (1984), que avaliou indicadores financeiros das cooperativas de crédito federais americanas antes e depois da instauração do seguro depósito no período de 1948 a 1980. Para tanto, subdividiu esse período de tempo em três: pré-seguro depósito (1948-1970), transição (1971 a 1973) e período do seguro depósito (1974 a 1980). De acordo com Clair (1984), espera-se que as cooperativas de crédito iniciem o período do seguro depósito em melhores condições financeiras que a dos períodos pré-seguro depósito e transição. Assim, a confirmação da hipótese de existência do problema de risco moral se daria caso houvesse um aumento progressivo do comportamento pró-risco após a instauração do seguro depósito, ou seja, no terceiro subperíodo ou período do seguro depósito (Clair, 1984). Este autor concluiu que a exposição ao risco de crédito cresceu significativamente depois da instauração do seguro depósito. Destaca-se que este procedimento de divisão dos períodos adotado por Clair (1984) em seu trabalho seminal foi adotado também no presente estudo. A conclusão de Clair (1984) é a mesma obtida por Fischer and Fournier (2002) que desenvolveram um modelo teórico e, por meio de simulações com o mesmo, demonstraram que o seguro depósito nas cooperativas de crédito induz ao problema de risco moral.

De modo geral, diversos fatores contribuem para determinar o quão grave será o problema de risco moral, ou seja, o quão maior será o grau de exposição ao risco das instituições financeiras em relação ao nível eficiente de exposição. Exemplos desses fatores são: a extensão da cobertura prometida pelo seguro depósito; a disponibilidade no mercado financeiro de ativos com altos retornos e, consequentemente, alto risco; e a intensidade pela qual as cooperativas de crédito buscam maximizar os seus resultados ou sobras.

De fato, se existe incentivo para que as cooperativas de crédito aumentem as sobras, receitas e disponibilidade de crédito, então, por conta do problema de risco moral aumentarão consideravelmente os seus níveis de exposição ao risco. Por exemplo, resultados empíricos obtidos por Keating (1979) sugerem que os gestores das cooperativas de crédito visam maximizar suas funções de utilidade condicionadas à restrição de haver um nível de benefício mínimo para os membros das cooperativas. Este resultado é consistente com a afirmação de que os gestores das cooperativas de crédito poderiam

\footnotetext{
${ }^{5}$ O Comitê de Supervisão Bancária da Basileia levou a transformações significativas nas regulações do setor em todo o mundo, ao sugerir várias alterações nas normas e procedimentos adotados externa e internamente no monitoramento das atividades e ao induzir muitos sistemas financeiros a melhorar de maneira substancial sua capitalização. Este acordo, de modo geral, passou por processos de revisão, e diversas alterações foram introduzidas no acordo original de modo a tornar o padrão de regulação bancária o mais adequado possível à difícil tarefa de regular a indústria bancária. Atualmente, os princípios da Basileia centram-se em três pilares: capitais mínimos requeridos, supervisão do sistema bancário e disciplina de mercado e transparência (BANCO CENTRAL DO BRASIL, 2006).
} 
ser recompensados individualmente através de honorários em função do aumento dos retornos (Keating, 1979).

Na década de 90, Kane and Hendershott (1996) analisaram como as diferenças na estrutura de incentivos restringem a atratividade de especuladores e as oportunidades de tomadores de risco para a administração e regulamentação das cooperativas de crédito. Esses autores encontraram pouco suporte para a hipótese de existência do problema de risco moral quando estimaram a solvência do National Credit Union Share Insurance Fund (NCUSIF) e constataram que ela superou consideravelmente o desempenho dos bancos e associações de poupança e empréstimo ao longo da década de 1980.

Ainda na mesma década, Karels and McClatchey (1999) avaliaram as cooperativas de crédito americanas no período de 1970 a 1977 e não encontraram evidências de que a adoção do seguro depósito aumentou o nível de exposição ao risco destas cooperativas. Esta mesma constatação é verificada na década seguinte no estudo de Hannafin and McKillop (2007) quando avaliaram o período de 1991 a 2005 e concluíram que o mecanismo de seguro depósito para as cooperativas de crédito irlandesas não levou os seus membros a um comportamento pró-risco.

Tratando especificamente dos bancos, Grossman (1992) comparou o grau de exposição ao risco das instituições de poupança e empréstimo, com e sem cobertura do seguro depósito, que operavam em regimes regulatórios mais e menos rigorosos durante a década de 30 nos Estados Unidos. As análises dos balanços patrimoniais indicaram que instituições recém-asseguradas estavam em posição de menor risco do que as suas contrapartes não asseguradas. Entretanto, Grossman (1992) argumenta que, possivelmente devido ao intenso acompanhamento das autoridades do seguro depósito antes de aceitarem uma instituição financeira, o problema de risco moral emerge de forma gradual.

Chan et al. (1992) analisaram o efeito do seguro depósito sobre o problema de risco moral quanto à sensibilidade ao risco e compatibilidade de incentivos. Eles demonstraram que se as instituições depositárias forem perfeitamente competitivas, ou seja, se o lucro médio do setor for zero, então, será impossível introduzir um mecanismo incentivo-compatível que contemple a sensibilidade ao risco na precificação do seguro depósito. Chan et al. (1992) defendem que a estrutura de prêmio insensível ao risco do seguro depósito encoraja as instituições depositárias a escolherem ativos excessivamente arriscados. Contudo, Pyle (1984) coloca que a precificação do seguro depósito sensível ao risco exigiria maiores informações sobre o depositante assegurado. Por exemplo, seria necessário se conhecer o grau de aversão ao risco e a função utilidade dos segurados, o que traz dificuldades à operacionalização desse tipo de precificação.

Admitindo que quando a teoria tem implicações ambíguas se torna particularmente interessante olhar as evidências empíricas, Demirgüç-Kunt and Detragiache (2002) investigaram os efeitos do seguro depósito sobre a estabilidade bancária de 61 países entre 1980 e 1997 e encontraram que o seguro depósito tende, em geral, a aumentar a probabilidade de ocorrência de crises bancárias, especialmente em países em que as taxas de juros bancárias são desreguladas e o ambiente institucional é fraco. Observaram ainda que o efeito negativo do sistema de seguro depósito sobre a estabilidade bancária tende a ser maior quando o seguro depósito é financiado e fortemente administrado, e quanto maior for a cobertura dada pelo seguro depósito aos depositantes.

Gropp and Vesala (2004) analisaram a relação entre o seguro depósito, o monitoramento dos devedores e o comportamento pró-risco dos bancos europeus na década de 90 . A partir de análise do setor bancário europeu, os autores mostraram que o seguro depósito pode reduzir o risco moral, se o mesmo exclui credores não-depositantes. Esta posição contrasta com o argumento frequentemente encontrado na literatura de que o seguro depósito induz ao problema de risco moral e incentiva o excessivo comportamento pró-risco (risk taking behavior) dos bancos (Gropp and Vesala, 2004).

Em síntese, o Quadro 1 apresenta as conclusões dos principais estudos que avaliaram o impacto do seguro depósito sobre o comportamento de risco das instituições financeiras. 
Quadro 1 - Estudos que avaliaram o impacto do seguro depósito sobre o comportamento de risco das instituições financeiras

\begin{tabular}{|c|c|c|}
\hline Autores & Analisam & Conclusões \\
\hline $\begin{array}{l}\text { Keeley (1990), Brewer III and } \\
\text { Mondschean (1994); Dreyfus et al. } \\
\text { (1994); Hassan et al. (1994); Kopcke } \\
\text { (2000); Milhaupt (1999); Brewer III } \\
\text { (1995); Carr et al. (1995); }\end{array}$ & Bancos & $\begin{array}{l}\text { Constataram que a presença do seguro } \\
\text { depósito encoraja os acionistas dos } \\
\text { bancos a adotarem políticas mais } \\
\text { arriscadas. }\end{array}$ \\
\hline $\begin{array}{l}\text { Wheelock e Wilson (1994) apud Gropp } \\
\text { and Vesala (2004) e Alston et al. (1994); }\end{array}$ & Bancos & $\begin{array}{l}\text { Não encontraram relação entre as } \\
\text { taxas de falência nos EUA e o seguro } \\
\text { depósito. }\end{array}$ \\
\hline $\begin{array}{l}\text { Grossman (1992), Wheelock (1992), } \\
\text { Thies e Gerlowski (1989) apud Gropp } \\
\text { and Vesala (2004); }\end{array}$ & Bancos & $\begin{array}{l}\text { Encontraram relação positiva e } \\
\text { significativa entre o seguro depósito e } \\
\text { o risk taking nos bancos. }\end{array}$ \\
\hline Demirgüç-Kunt and Detragiache (2002); & Bancos & $\begin{array}{l}\text { Constataram que o seguro depósito } \\
\text { aumenta significativamente a } \\
\text { probabilidade de crises bancárias. }\end{array}$ \\
\hline Gropp and Vesala (2004); & Bancos & $\begin{array}{l}\text { Averiguaram que nos bancos europeus } \\
\text { o seguro depósito explícito reduziu } \\
\text { significativamente o problema do risco } \\
\text { moral. }\end{array}$ \\
\hline Black and Dugger (1981); & Cooperativas de crédito & $\begin{array}{l}\text { Constataram aumento do risk } \\
\text { taking após a instauração do seguro } \\
\text { depósito nas cooperativas de crédito } \\
\text { americanas. }\end{array}$ \\
\hline Clair (1984); & Cooperativas de crédito & $\begin{array}{l}\text { Concluíram que aumentou o } \\
\text { comportamento de risco após a } \\
\text { introdução do seguro depósito nas } \\
\text { cooperativas de crédito americanas. }\end{array}$ \\
\hline Kane and Hendershott (1996); & Cooperativas de crédito & $\begin{array}{l}\text { Encontraram pouco suporte para } \\
\text { o risco moral quando estimaram a } \\
\text { solvência das cooperativas de crédito } \\
\text { americanas. }\end{array}$ \\
\hline Karels and McClatchey (1999); & Cooperativas de crédito & $\begin{array}{l}\text { Não verificaram evidências de que } \\
\text { o seguro depósito aumenta o risk } \\
\text { taking nas cooperativas de crédito } \\
\text { americanas. }\end{array}$ \\
\hline Fischer and Fournier (2002); & Cooperativas de crédito & $\begin{array}{l}\text { Certificaram, via simulações, que } \\
\text { a introdução do seguro depósito } \\
\text { aumenta o nível de risco nas } \\
\text { cooperativas de crédito, porém em } \\
\text { menor intensidade se comparado } \\
\text { com o aumento de risco do sistema } \\
\text { bancário. }\end{array}$ \\
\hline Hannafin and McKillop (2007); & Cooperativas de crédito & $\begin{array}{l}\text { Não verificaram aumento do risco nas } \\
\text { cooperativas de crédito irlandesas após } \\
\text { a introdução do seguro depósito. }\end{array}$ \\
\hline
\end{tabular}

Fonte: Adaptado pelos autores com base nos trabalhos citados no quadro. 
Pelo Quadro 1, é possível observar que a maioria dos trabalhos sobre bancos concorda que o seguro depósito induz ao problema de risco moral no sistema bancário, o que não é observado em se tratando dos trabalhos empíricos relativos às cooperativas de crédito. De fato, as conclusões dos trabalhos sobre cooperativas de crédito são conflitantes.

\section{METODOLOGIA}

A estratégia adotada para se testar a hipótese de que a instauração do Fundo Garantidor do Sicoob (FGS) pelo Sistema das Cooperativas de Crédito do Brasil (Sicoob) não induziu ao problema de risco moral nas cooperativas de crédito brasileiras consistiu em investigar se há uma tendência de aumento na exposição ao risco das cooperativas após a instauração do FGS em outubro de 2005 . Em não se detectando tal tendência, conclui-se que o FGS não induziu ao problema de risco moral nas cooperativas de crédito brasileiras; caso contrário, conclui-se que o FGS induziu ao problema de risco moral nas cooperativas de crédito brasileiras. Note que esta estratégia é idêntica àquela utilizada por Clair (1984) em um estudo sobre as cooperativas norte-americanas.

Os painéis de dados utilizados no presente estudo foram construídos com base em cento e oitenta cooperativas de crédito participantes do FGS e que tiveram os balanços disponibilizados ${ }^{6}$ para todo o período entre janeiro de 2000 e junho de 2008 (102 observações por cooperativa). Às cento e oitenta cooperativas na amostra correspondem a $61,43 \%$ das cooperativas de crédito filiadas ao Sicoob e participantes do FGS no período de janeiro de 2000 a junho de 2008 . Note que os painéis de dados deveriam conter um total de 18.360 observações, mas por conta de dados indisponíveis para algumas variáveis para algumas cooperativas da amostra os painéis de dados utilizados são não balanceados, contendo 16.089 observações.

O modelo econométrico base foi especificado tomando os estudos empíricos de Clair (1984), Karels and McClatchey (1999) e Hannafin and McKillop (2007) e o modelo teórico de Fischer and Fournier (2002). Assim, a relação de interesse é capturada pela regressão de referência especificada pela equação (1).

$$
\begin{aligned}
& \text { basileia }_{i t}=\beta_{0}+\beta_{1} d_{\text {tamm }_{i t}}+\beta_{2} \text { dtamg }_{i t}+\beta_{3} \text { idade }_{i t}+\beta_{4} d d o m i_{i t}+\beta_{5} t_{i t}+ \\
& \quad+\beta_{6} \operatorname{dpsd}_{i t}+\beta_{7}\left(\operatorname{dpsd}_{i t} \cdot t_{i t}\right)+\beta_{8} Y_{i t-1}+\beta_{9} Y_{i t}+\beta_{10}\left(d t s d_{i t} \cdot t_{i t}\right)+\nu_{i}+\epsilon_{i t}
\end{aligned}
$$

em que $i=1, \ldots, 180$ indexa a $i$-ésima cooperativa de crédito da amostra; $t=1, \ldots, 102$ indexa o $t$-ésimo mês do período de janeiro de 2000 a junho de 2008; $\beta_{0}$ é o intercepto do modelo; $\beta_{k}$ é o coeficiente da $k$-ésima variável explicativa; $\nu_{i}$ denota os efeitos não observáveis e invariantes no tempo da $i$-ésima cooperativa de crédito no caso do modelo de efeitos fixos; no caso do modelo de efeitos aleatórios $\nu_{i}$ denota erros aleatórios identicamente e independentemente distribuídos com média zero e variância constante; e $\epsilon_{i t}$ é o erro aleatório denominado de "erro usual da regressão" (Baltagi, 2005). A descrição da variável dependente e das variáveis explicativas do modelo (1) e os sinais esperados dos seus coeficientes são apresentados no Quadro 2.

A seguir, serão apresentadas as principais características do Fundo Garantidor do Sicoob.

\footnotetext{
${ }^{6}$ Os dados foram fornecidos pelo Banco Central do Brasil e são de caráter confidencial.
} 
Quadro 2 - Descrição das variáveis do modelo econométrico (1)

\begin{tabular}{|c|c|c|}
\hline Variável & Descrição & Relação esperada \\
\hline basileia $_{i t}$ & $\begin{array}{l}\text { De acordo com o Banco Central } \\
\text { do Brasil, o conceito internacional } \\
\text { definido pelo Comitê de Basileia } \\
\text { recomenda a relação mínima } \\
\text { de } 8 \% \text { entre o Patrimônio de } \\
\text { Referência (PR) ou Patrimônio } \\
\text { Base e os riscos ponderados } \\
\text { conforme regulamentação em } \\
\text { vigor (Patrimônio de Referência } \\
\text { Exigido - } P R E) \text {. No Brasil, } \\
\text { a relação mínima exigida é } \\
\text { estabelecida pelo fator } F \text {, de } \\
\text { acordo com a Resolução n } \\
\text { 3.490, de } 29 \text { de agosto de } 2007 \text {, } \\
\text { e Circular n. }{ }^{\circ} 3.360 \text {, de } 12 \text { de } \\
\text { setembro de } 2007 \text {, devendo } \\
\text { ser observado o valor de } 0,11 \\
\text { para as instituições financeiras } \\
\text { autorizadas a funcionar pelo } \\
\text { Banco Central do Brasil, incluindo } \\
\text { as cooperativas de crédito filiadas } \\
\text { a uma cooperativa central, que } \\
\text { são objetos de estudo do presente } \\
\text { estudo. Assim, o índice de } \\
\text { Basileia }{ }^{7} \text { que é um indicador de } \\
\text { adequação do capital é calculado } \\
\text { segundo a fórmula: Basileia }= \\
P R R^{*} 100 /(P R E / f a t o r \\
\text { Considera-se desenquadrada } \\
\text { em relação ao limite de } \\
\text { compatibilização do Patrimônio de } \\
\text { Referência }(P R) \text { com o Patrimônio } \\
\text { de Referência Exigido ( } P R E) \text {, a } \\
\text { instituição cujo } P R \text { for inferior } \\
\text { ao } P R E \text {. Isto é, quando o seu } \\
\text { patrimônio for insuficiente para } \\
\text { cobrir os riscos decorrentes de } \\
\text { suas operações ativas, passivas } \\
\text { e registradas em contas de } \\
\text { compensação. }\end{array}$ & $\begin{array}{l}\text { Menores valores de indicadores } \\
\text { de adequação do capital indicam } \\
\text { menor exposição ao risco. Com } \\
\text { isso, quanto menor for o índice de } \\
\text { Basileia, maior será a exposição da } \\
\text { cooperativa de crédito ao risco. }\end{array}$ \\
\hline
\end{tabular}

${ }^{7}$ Para maiores detalhes sobre o índice de Basileia podem ser obtidos no sítio do Banco Central do Brasil em www.bcb.gov.br. 
Quadro 2 - Descrição das variáveis do modelo econométrico (1) - continuação

\begin{tabular}{|c|c|c|}
\hline Variável & Descrição & Relação esperada \\
\hline$d t a m m_{i t}$ e $d t a m g_{i t}$ & $\begin{array}{l}\text { Variáveis dummy para o tamanho } \\
\text { da cooperativa, } 8,9 \text { tal que: } \\
\bullet \text { dtammit recebe o valor } 1 \text { quando o } \\
\text { ativo total da cooperativa de crédito } \\
\text { está dentro da faixa de } 33 \% \text { a } 66 \% \\
\text { do ativo total da amostra, e } 0 \text { caso } \\
\text { contrário. - dtamg } g_{i t} \text { recebe o valor } 1 \\
\text { quando o ativo total da cooperativa de } \\
\text { crédito é superior a } 66 \% \text { do ativo total } \\
\text { da amostra, e } 0 \text { caso contrário. }\end{array}$ & $\begin{array}{l}\text { Karels and McClatchey (1999) propõem } \\
\text { que se o tamanho da cooperativa } \\
\text { de crédito refletir a experiência dos } \\
\text { seus gestores, quanto maior for a } \\
\text { cooperativa, mais sofisticado será o seu } \\
\text { gerenciamento, o que a torna capaz de } \\
\text { operar com menor liquidez e capital do } \\
\text { que outra instituição similar de menor } \\
\text { tamanho. Desta forma, propõem } \\
\text { que cooperativas maiores se exponham } \\
\text { mais ao risco do que cooperativas } \\
\text { menores, ceteris paribus. Portanto, } \\
\text { esperam-se sinais negativos para os } \\
\text { coeficientes dessas duas variáveis. }\end{array}$ \\
\hline$i d a d e_{i t}$ & $\begin{array}{l}\text { Denota o tempo de existência da } \\
\text { cooperativa em anos. }\end{array}$ & $\begin{array}{l}\text { Segundo Melvin, Davis e Fischer (1977) } \\
\text { apud Clair (1984), a probabilidade de } \\
\text { fracasso de cooperativas de crédito } \\
\text { recém-criadas é aproximadamente } \\
40 \% \text { e declina com o tempo tal que } \\
\text { se aproxima de zero após } 16 \text { anos } \\
\text { de operação da cooperativa. Com } \\
\text { isso, espera-se que cooperativas } \\
\text { mais antigas se exponham menos } \\
\text { ao risco, ceteris paribus. Discordando } \\
\text { disso, Karels and McClatchey (1999) } \\
\text { defendem que a idade tem um efeito } \\
\text { negativo sobre um indicador de } \\
\text { Adequação do Capital. Isso porque } \\
\text { cooperativas de crédito podem } \\
\text { naturalmente aumentar o seu capital } \\
\text { via incremento das reservas de modo } \\
\text { que cooperativas mais velhas tendem } \\
\text { a apresentar maior base de capital, o } \\
\text { que lhes propiciaria operar com maior } \\
\text { nível de risco. Portanto, espera-se um } \\
\text { sinal negativo para o coeficiente dessa } \\
\text { variável. }\end{array}$ \\
\hline
\end{tabular}

\footnotetext{
${ }^{8}$ Optou-se por trabalhar com a variável "tamanho" utilizando variáveis dummies, pois o valor do ativo total foi utilizado (por meio da taxa de crescimento dos ativos) como alternativa para avaliar choques exógenos, conforme descrito na última linha do Quadro 2.

${ }^{9}$ As cooperativas cujo ativo total se situava em até 33\% do total dos ativos da amostra (primeiro tercil) foram classificadas como pequenas, as cooperativas cujo ativo total se situava entre $33 \%$ e $66 \%$ (segundo tercil) foram classificadas como médias, e as com ativo total acima de $66 \%$ (terceiro tercil da amostra) foram consideradas como grandes cooperativas.
} 


\section{Quadro 2 - Descrição das variáveis do modelo econométrico (1) - continuação}

\begin{tabular}{|c|c|c|}
\hline Variável & Descrição & Relação esperada \\
\hline ddomit & $\begin{array}{l}\text { Variável dummy para o índice de dominação, } \\
\text { tal que: ddomi } i_{i t} \text { recebe o valor } 1 \text { se } \\
\text { a cooperativa é dominada por membros } \\
\text { tomadores de recursos; e recebe o valor zero } \\
\text { se a cooperativa é dominada por membros } \\
\text { aplicadores ou poupadores. A classificação } \\
\text { das cooperativas em nossa amostra foi } \\
\text { realizada seguindo a metodologia proposta } \\
\text { por Patin and McNiel (1991). }{ }^{10}\end{array}$ & $\begin{array}{l}\text { De acordo com Fischer and Fournier (2002), } \\
\text { cooperativas dominadas por tomadores } \\
\text { tendem a operar com maior nível de risco. } \\
\text { Espera-se, portanto, um sinal negativo para } \\
\text { o coeficiente dessa variável. }\end{array}$ \\
\hline$t_{i t}$ & Variável tendência. & Sem sinal esperado. \\
\hline$d p s d_{i t}$ e $d t s d_{i t}$ & $\begin{array}{l}\text { Variáveis dummy para os períodos de } \\
\text { transição }(d t s d) \text { e pós instauração }(d p s d) \text { do } \\
\text { Fundo Garantidor do Sicoob }(\mathrm{FGS}) \text {, tal que: } \\
\bullet \quad d t s d_{i t} \text { recebe o valor } 1 \text { para o período } \\
\text { entre outubro de } 2005 \text { e março de } 2007 \text {; e } \\
\text { caso contrário, recebe o valor zero; } \bullet d p s d_{i t} \\
\text { recebe o valor } 1 \text { para o período entre abril de } \\
2007 \text { e junho de } 2008 \text {; caso contrário, recebe } \\
\text { o valor zero. }\end{array}$ & $\begin{array}{l}\text { O cumprimento de altos padrões financeiros } \\
\text { durante o período de transiçãa teria dois } \\
\text { efeitos: a redução da exposição ao risco } \\
\text { fruto da melhora da condição financeira das } \\
\text { cooperativas, traduzido em um coeficiente } \\
\beta_{10} \text { positivo; e, as cooperativas iniciam } \\
\text { o período sob seguro depósito em melhor } \\
\text { condição financeira do que a do período } \\
\text { base que é anterior a transição e instauração } \\
\text { do seguro depósito, o que se traduz em } \\
\text { um coeficiente } \beta_{6} \text { com sinal positivo (Clair, } \\
\text { 1984). Se houver aumento progressivo no } \\
\text { comportamento pró risco após a instauração } \\
\text { do seguro depósito, o que é o mesmo que } \\
\text { rejeitar a hipótese de que o FGS não induziu } \\
\text { ao problema de risco moral, o coeficiente } \\
\beta_{7} \text { deverá ser significativo e negativo (Clair, } \\
\text { 1984). }\end{array}$ \\
\hline$Y_{i t}$ e $Y_{i t-1}$ & $\begin{array}{l}\text { - Denota a Taxa de Crescimento do Ativo } \\
=\text { (ativo total }{ }_{t}-\text { ativo total } t-1 \text { )/ativo } \\
\text { total }_{t-1} \text {. }\end{array}$ & $\begin{array}{l}\text { Irão captar choques exógenos e movimentos } \\
\text { cíclicos no indicador de risco (CLAIR, 1984). } \\
\text { Na regressão, espera-se que } \beta_{9} \text { seja negativo } \\
\text { (Clair, 1984), pois como } Y_{t} \text { é a taxa de } \\
\text { crescimento do ativo, um choque exógeno } \\
\text { que aumente o ativo, provavelmente } \\
\text { ocorrerá à custa da redução na taxa de } \\
\text { capital, ou seja, da redução nas sobras } \\
\text { indivisíveis e reservas e/ou aumento dos } \\
\text { empréstimos. O intervalo de tempo entre } \\
\text { o crescimento do ativo e o crescimento do } \\
\text { capital provoca um declínio na "adequação } \\
\text { do capital" por isso espera-se que } \beta_{9} \text { seja } \\
\text { negativo. }\end{array}$ \\
\hline
\end{tabular}

Fonte: Elaborado pelos autores.

\footnotetext{
${ }^{10} \mathrm{~A}$ metodologia e os resultados dos Índices de Dominação das cooperativas de crédito mineiras não são reportados por questões de espaço e objetividade. Assim, o leitor interessado deve requisitá-los diretamente dos autores.
} 


\subsection{Características do Fundo Garantidor do Sicoob}

O Fundo Garantidor do Sicoob (FGS) é uma associação civil, sem fins lucrativos e com personalidade jurídica de direito privado, que tem por objeto prestar garantia de depósitos à vista e a prazo mantidos pelos associados nas singulares associadas, por depositante, no caso de ocorrência dos seguintes eventos:

a) liquidação extrajudicial de singulares associadas, decretada pelo Banco Central do Brasil;

b) liquidação ordinária de singulares associadas, por motivo de insolvência, decidida por assembléia geral; e

c) descredenciamento de singulares associadas do convênio firmado com o Bancoob para compensação de cheques e outros papéis, por motivo de insolvência, confirmada pelo órgão de auditoria do Sicoob-Brasil, além de garantir os créditos recebidos e provisionados pela singular incorporadora (SICOOB, 2006).

As cooperativas singulares poderão ser admitidas como associadas ao FGS se:

a) apresentarem condições adequadas de equilíbrio econômico-financeiro;

b) possuírem níveis adequados de disponibilidade e liquidez, consoantes as exigências previstas em normativos instituídos para o Sistema Sicoob;

c) estiverem em conformidade com a legislação, com as normas do Conselho Monetário Nacional, do Banco Central do Brasil, do Sicoob-Brasil e da Central à qual estão associadas e com a regulamentação do FGS;

d) estiverem em dia com o envio das informações solicitadas pelo Sicoob-Brasil;

e) forem auditadas, regularmente, pela Central à qual estão associadas, cumprindo as notificações resultantes dos trabalhos de auditoria;

f) mantiverem os recursos disponíveis aplicados exclusivamente na Central à qual estão associadas, salvo situações excepcionais, cujas justificativas serão objeto de deliberação pelo Conselho de Administração do FGS;

g) estiverem em conformidade com os normativos aplicáveis às marcas Sicoob e Bancoob;

h) estiverem em dia com as obrigações legais, tributárias e previdenciárias;

i) cumprirem os dispositivos previstos no Estatuto Social da Central à qual estão associadas, os dispositivos previstos em convênios e contratos firmados com o Bancoob, com ou sem interveniência da Central;

j) recolherem a contribuição inicial e as contribuições mensais subsequentes obrigatórias, de acordo com regras específicas constantes no regulamento do FGS; e

k) estiverem captando depósitos à vista e a prazo por período superior a 6 (seis) meses consecutivos (SICOOB, 2006).

O Quadro 3 sintetiza alguma das principais características do FGS. Note-se que existem várias características similares entre o FGC e o FGS, tais como: ambos constituem um seguro depósito explícito, o pagamento é realizado por depositante, são sistemas com financiamento permanente, tanto a fonte quando a administração dos fundos são privadas, não mencionam cobertura de depósito em moeda no exterior, nem existência de cosseguro e de prêmios ajustados ao risco. A principal diferença entre os dois fundos garantidores é que a associação ao FGC é compulsória, ao passo que a associação ao FGS é voluntária. Além disso, o FGC e FGS também diferem quando ao limite de cobertura. 
Quadro 3 - Resumo das características do seguro depósito para bancos brasileiros e para cooperativas de crédito filiadas ao Sicoob

\begin{tabular}{|c|c|c|}
\hline Características & Fundo Garantidor de Crédito (FGC) & Fundo Garantidor do Sicoob (FGS) \\
\hline Aplicado & Bancos Brasileiros & Cooperativas de crédito \\
\hline Seguro depósito & Explícito & Explícito \\
\hline Ano da legalização/ revisado & $1995 / 2002 / 2004 / 2006 / 2008$ & 2005 \\
\hline $\begin{array}{l}\text { Cobertura de depósito em moeda } \\
\text { no Exterior }\end{array}$ & Não & Não \\
\hline $\begin{array}{lll}\begin{array}{l}\text { Cobertura de } \\
\text { interbancário }\end{array} & \text { depósito } \\
\end{array}$ & Não & - \\
\hline Limite de cobertura & $\mathrm{R} \$ 70.000,00$ & $\mathrm{RS} 60.000,00$ \\
\hline Existência de cosseguro & Não & Não \\
\hline Pagamento por depositante & Sim & Sim \\
\hline $\begin{array}{l}\text { Sistema é permanentemente } \\
\text { financiado }\end{array}$ & Sim & Sim \\
\hline Contribuição fixa & $\begin{array}{l}\text { Contribuição mensal de } 0,0125 \% \\
\text { do montante dos saldos das contas } \\
\text { correspondentes às obrigações } \\
\text { objeto de garantia }\end{array}$ & $\begin{array}{l}\text { Contribuição da } \text { Associada } \\
\text { Singular: }^{11} \bullet \quad 0,035 \% \text { sobre } \\
\text { o saldo médio dos depósitos } \\
\text { mensais,à vista e a prazo, } \\
\text { menores ou iguais a } \mathrm{R} \$ 60.000,00 \text {. } \\
\text { - 0,015\% sobre o valor médio dos } \\
\text { depósitos mensais, excedentes a } \\
\mathrm{R} \$ 60.000,00 \text {. }\end{array}$ \\
\hline Prêmio ajustado ao risco & Não & Não \\
\hline Associação compulsória & Sim & Não \\
\hline Fonte dos Fundos & Privada & 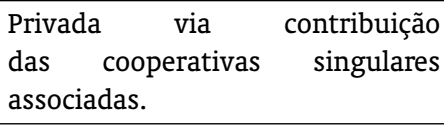 \\
\hline Administração & Privada & $\begin{array}{l}\text { Privada por meio do Conselho } \\
\text { de Administração formado por } \\
\text { Membros da Central associada ao } \\
\text { Sicoob Brasil. }\end{array}$ \\
\hline
\end{tabular}

Fonte: Adaptado do FGC (2011), FGS (2011) e SICOOB (2006).

\footnotetext{
${ }^{11}$ O valor mínimo mensal da contribuição é de R\$ 300,00.
} 


\subsection{Procedimentos para estimação do modelo econométrico}

A estratégia utilizada para selecionar a melhor especificação dos modelos consistiu em primeiro estimar os modelos MQO agrupado (pooled OLS) e efeitos fixos para testar, via teste Chow (teste F), a hipótese nula de que MQO agrupado é preferível a efeitos fixos. No segundo passo, estima-se o modelo com efeitos aleatórios e, utilizando-se o teste Breusch-Pagan (teste do tipo multiplicador de Lagrange), testa-se a hipótese nula de que MQO agrupado é preferível ao modelo com efeitos aleatórios. O terceiro passo consiste em testar pelo teste de Hausman a hipótese nula de que o estimador de efeitos aleatórios, por ser consistente e eficiente, é preferível ao estimador do modelo com efeitos fixos que é apenas consistente. Se com os três passos anteriores o modelo com efeitos fixos for escolhido, executa-se um quarto passo que consiste em se testar para autocorrelação dos erros via teste proposto por Wooldridge (2002) e testar para heterocedasticidade de grupo por um teste de Wald. Finalmente, se autocorrelação e heterocedasticidade forem confirmadas, o modelo com efeitos fixos é re-estimado via Mínimos Quadrados Generalizados Factíveis (Feasible Generalized Least Squares ou FGLS) como sugerido por Judge et al. (1985) e Davidson and MacKinnon (1993). Note-se que Baltagi and Wu (1999) e Hansen (2007) também utilizaram estimadores FGLS, pois detectaram que os erros em seus modelos de dados em painel não balanceados eram autocorrelacionados.

\section{RESULTADOS E DISCUSSÃO}

A Tabela 1 apresenta as variáveis não dummies utilizadas nas estimações do modelo (1) e suas estatísticas descritivas, média e desvio-padrão em parênteses.

Table 1: Variáveis, suas médias e desvios-padrão entre parênteses para o período de 2000 a 2008 por ano

\begin{tabular}{|c|c|c|c|c|c|c|c|c|c|c|}
\hline \multirow[t]{2}{*}{ Variável } & De 2000 & 2000 & 2001 & 2002 & 2003 & 2004 & 2005 & 2006 & 2007 & 2008 \\
\hline & a 2008 & & & & & & & & & \\
\hline Índice de & 34,432 & nd & 2,96 & 32,96 & 35,271 & 42,941 & 42,01 & 42,692 & 39,704 & 39,368 \\
\hline \multirow[t]{2}{*}{ idade $_{i t}$} & 12,25 & 8,498 & 9,499 & 10,499 & 11,499 & 12,501 & 13,502 & 14,502 & 15,502 & 16,253 \\
\hline & $-7,291$ & $-6,873$ & $-6,873$ & $-6,873$ & $-6,873$ & $-6,873$ & $-6,873$ & $-6,873$ & $-6,873$ & $-6,87$ \\
\hline$Y_{i t}$ (Taxa de & 0,025 & 0,034 & 0,024 & 0,03 & 0,022 & 0,024 & 0,02 & 0,023 & 0,021 & 0,024 \\
\hline
\end{tabular}

Os resultados dos testes indicaram que o modelo de efeitos fixos é preferível aos modelos MQO agrupado (teste Chow) e efeitos aleatórios (teste Breusch-Pagan) como se pode verificar pelos resultados apresentados na última linha da Tabela 2. Tais resultados foram reportados de forma sintética por questões de espaço e objetividade, de modo que o leitor interessado pode requisitar maiores detalhes diretamente aos autores. O mesmo pode ser dito para os testes de Wooldridge (2002) e Wald que não permitiram rejeitar as hipóteses, respectivamente, de autocorrelação e heterocedasticidade de grupo (vide última linha da Tabela 2). Diante de tais resultados, a Tabela 2 apresenta somente os resultados da estimação FGLS do modelo com efeitos fixos, com destaque em cinza para as linhas referentes às três variáveis do modelo (1): $d t s d_{i t} \cdot t_{i t} ; d p s d_{i t}$ e $d p s d_{i t} \cdot t_{i t}$. Note-se que o modelo é globalmente significante pelo teste de Wald apresentado na antepenúltima linha da Tabela 2.

Pela Tabela 2, as variáveis dummies para o tamanho da cooperativa (dtammit e dtamgit) apresentaram coeficientes positivos, estatisticamente e individualmente significativos ao nível de $1 \%$ de probabilidade. Com base neles, ceteris paribus, cooperativas de tamanho pequeno (categoria base) 
Table 2: Estimativa FGLS do modelo (1) com efeitos fixos para as cooperativas de crédito filiadas ao Sicoob, no período de janeiro de 2000 a junho de 2008

\begin{tabular}{|c|c|}
\hline \multirow{2}{*}{$\begin{array}{l}\text { Variável } \\
\text { Explicativa }\end{array}$} & Variável Dependente \\
\hline & Índice de Basileia \\
\hline \multirow[t]{2}{*}{ dtamm $_{i t}$} & $2,8321^{* * *}$ \\
\hline & $-0,6112$ \\
\hline \multirow[t]{2}{*}{$d t a m g_{i t}$} & $2,3612^{* * *}$ \\
\hline & $-0,6674$ \\
\hline \multirow[t]{2}{*}{ idade $_{i t}$} & $-45,7328^{* * *}$ \\
\hline & $-15,9$ \\
\hline \multirow{2}{*}{$d d o m i_{i t}$} & $0,4768^{* * *}$ \\
\hline & $-0,1806$ \\
\hline \multirow[t]{2}{*}{$t_{i t}$} & $4,2858^{* * *}$ \\
\hline & $-1,33$ \\
\hline \multirow[t]{2}{*}{$d p s d_{i t}$} & $68,4000^{* * *}$ \\
\hline & $-4,6861$ \\
\hline \multirow[t]{2}{*}{$d p s d_{i t}^{*} t_{i t}$} & $-0,8680^{* * *}$ \\
\hline & $-0,0519$ \\
\hline \multirow[t]{2}{*}{$Y_{i t-1}$} & $-2,6900^{* * *}$ \\
\hline & $(0,4060)_{(A T)}$ \\
\hline \multirow[t]{2}{*}{$Y_{i t}$} & $-5,8800^{* * *}$ \\
\hline & $(0,4110)_{(A T)}$ \\
\hline \multirow[t]{2}{*}{$d t s d_{i t}^{*} t_{i t}$} & $-0,0728^{* * *}$ \\
\hline & $-0,0043$ \\
\hline \multirow[t]{2}{*}{ Constante } & $243,8285^{* * *}$ \\
\hline & $-86,3082$ \\
\hline $\mathrm{N}^{\circ}$ de observações & 16.089 \\
\hline $\mathrm{N}^{\circ}$ de Grupos & 180 \\
\hline $\mathrm{N}^{\circ}$ mín.de obs.p/Grupo & 3 \\
\hline Wald $\chi^{2}(189)$ & $9.229,84$ \\
\hline Prob $>\chi^{2}(189)$ & 0,000 \\
\hline Resultados dos testes: Teste Chow: $\mathrm{F}(179,15899)=12.70$ & Prob $>F=0,0000$ \\
\hline Teste Breusch e Pagan: $\operatorname{chi} 2(1)=8187,57$ & Prob $>$ chi $2=0,0000$ \\
\hline Teste de Hausman: $\operatorname{chi} 2(7)=42,31$ & Prob $>$ chi $2=0,0000$ \\
\hline Teste de Wooldridge para autocorrelação: $\mathrm{F}(1,179)=7,661$ & Prob $>F=0,0062$ \\
\hline Teste de Wald para heterocedasticidade: $\operatorname{chi} 2(180)=1,5 e+07$ & Prob $>$ chi $2=0,0000$ \\
\hline Obs.: ${ }^{* * *}$ denota significante a $1 \%$; ${ }^{* *}$ denota significante a $5 \%$; & \\
\hline * denota significante a 10\%; Erros-padrão estão entre parênteses; (AT) den & ta Ativo Total. \\
\hline Fonte: Resultados da Pesquisa. & \\
\hline
\end{tabular}


se expõem mais ao risco do que as de tamanho grande e estas se expõem mais ao risco que as de tamanho médio. Note-se que esses resultados não estão em linha com os obtidos por Karels and McClatchey (1999) para cooperativas de crédito americanas quando constataram que quanto maior era a cooperativa, maior era a sua exposição ao risco. Apesar disso, não há uma teoria inequívoca que invalide os nossos resultados. De fato, Karels and McClatchey (1999) justificaram os seus resultados com base na premissa de que o tamanho da cooperativa de crédito reflete a experiência dos seus gestores de modo que quanto maior for a cooperativa, mais sofisticado seria o seu gerenciamento e, portanto, a sua capacidade de se expor ao risco. No caso das cooperativas de crédito brasileiras, simplesmente, não é esse o caso.

O coeficiente da variável $i d a d e_{i t}$ foi estatisticamente significativo (vide Tabela 2 ) e negativo, o que indica que quanto mais antiga for a cooperativa, ceteris paribus, menor será o valor esperado do seu índice de adequação do capital, no caso o índice de Basileia, ou seja, maior será a sua exposição ao risco. Em linha com esses resultados, Karels and McClatchey (1999) argumentam que cooperativas mais antigas têm um provável aumento da base de capital, o que permitiria um comportamento de maior exposição ao risco.

A variável dummy ddomi $i_{i t}$ para dominação da cooperativa por membros tomadores de recursos foi estatisticamente e individualmente significante, com coeficiente positivo (vide Tabela 2). Com base nisso, espera-se que cooperativas dominadas por membros tomadores de recursos, ceteris paribus, apresentem índices de Basileia com valores mais elevados, ou seja, que se exponham menos ao risco do que os outros tipos de cooperativas de crédito (neutras ou dominadas por membros aplicadores/poupadores de recursos).

A variável tendência $t_{i t}$ apresentou coeficiente positivo e estatisticamente e individualmente significante (vide Tabela 2). Com base nisso, espera-se um crescimento mensal de 4,2858 no índice de Basileia das cooperativas de crédito brasileiras, ceteris paribus, ou seja há uma tendência de redução no nível de exposição ao risco das cooperativas na amostra ao longo do tempo.

O efeito da taxa de crescimento do ativo sobre o nível de risco assumido pelas cooperativas filiadas ao Sicoob é captado pelas variáveis $Y_{i t(A T)}$ e $Y_{i t-1(A T)}$. As estimativas dos seus coeficientes foram negativas e estão de acordo com Clair (1984). Clair (1984) propõe que qualquer choque exógeno que aumente o ativo da cooperativa se dará à custa da redução na taxa de capital, ou seja, da redução nas sobras indivisíveis e reservas e/ou aumento na contratação de empréstimos. Em outras palavras, o autor defende que o aumento do capital de cooperativas de crédito causa aumento em seus níveis de exposição ao risco. Como é necessário certo tempo para que o crescimento do ativo se reverta em crescimento do capital há um declínio na "adequação do capital" e, por isso, espera-se que $\beta_{9}$ (vide equação (1)) seja negativo.

O sinal da estimativa e a significância individual das variáveis $d p s d_{i t}, d p s d_{i t} \cdot t_{i t}$ e $d t s d_{i t} * t_{i t}$ são cruciais para o teste da hipótese de que a instauração do FGS não induziu ao problema de risco moral nas cooperativas de crédito filiadas brasileiras. Os resultados na Tabela 2 mostram que cada uma dessas três variáveis foi estatisticamente e individualmente significante ao nível de $1 \%$ de probabilidade, o que constitui um forte indício a favor da rejeição dessa hipótese.

Como a variável tendência assume somente valores positivos, o sinal do coeficiente $\beta_{10}$ determina, por completo, o sentido do efeito do período de transição do FGS sobre o índice de Adequação do Capital medido pelo índice de Basileia. ${ }^{8} \mathrm{o}$ coeficiente $\beta_{10}$ da variável $d t s d_{i t} \cdot t_{i t}$, é estatisticamente e individualmente significante e apresenta estimativa com sinal negativo (vide Tabela 2), indicando uma tendência de aumento da exposição ao risco das cooperativas no período de transição para o FGS. Esse resultado empírico para as cooperativas de crédito brasileiras não corrobora a hipótese de Clair (1984) que as cooperativas de crédito cumpririam altos padrões financeiros no período de transição até a instauração do seguro depósito e, por isso, haveria uma redução em seus níveis de exposição ao risco nesse período.

\footnotetext{
${ }^{8}$ Note que a derivada parcial do modelo (1) com respeito a $d t s d_{i t}$ é $\beta_{10} t_{i t}$.
} 
As variáveis $d p s d_{i t}$ e $d p s d_{i t} \cdot t_{i t}$ captam o efeito sobre o nível de exposição ao risco das cooperativas após a instauração do seguro depósito. Note que o efeito total da instauração do seguro depósito sobre o indicador de Adequação de Capital é dado pela derivada parcial da equação (1) com respeito a variável $d p s d_{i t}$ que é $\beta_{6}+\beta_{7} t_{i t}$, onde: $\beta_{6}$ é o coeficiente da variável $d p s d_{i t}$ e $\beta_{7}$ é o coeficiente da variável $d p s d_{i t} \cdot t_{i t}$. Note que os resultados apresentados na Tabela 2 indicam, respectivamente, o sinal positivo e o sinal negativo para as estimativas dos coeficientes $\beta_{6}$ e $\beta_{7}$. O sinal positivo e a elevada magnitude da estimativa de $\beta_{6}$ indicam haver uma forte redução no grau de exposição ao risco (melhora da Adequação do Capital) das cooperativas de crédito brasileiras após a instauração do Fundo Garantidor do Sicoob (FGS). Contudo, o sinal negativo da estimativa de $\beta_{7}$ indica uma tendência de aumento do grau de exposição ao risco (piora da Adequação do Capital) das cooperativas de crédito brasileiras com a implantação do FGS. Esses dois resultados estão em linha com o trabalho de Clair (1984).

Note-se que a rejeição da hipótese de que o coeficiente $\beta_{7}$ associado a variável $d p s d_{i t} \cdot t_{i t}$ é zero implica na rejeição da hipótese de que a instauração do FGS não induziu ao problema de risco moral. Assim, a significante tendência de aumento na exposição ao risco das cooperativas brasileiras evidenciado após a instauração do FGS indica que a instauração do FGS induziu ao problema de risco moral nas cooperativas de crédito brasileiras.

Note-se que a única diferença entre os resultados obtidos no presente trabalho e aqueles obtidos por Clair (1984) para cooperativas americanas foi a obtenção aqui de uma tendência de aumento (redução) da exposição ao risco das cooperativas de crédito brasileiras no período de transição até o FGS.

\section{CONCLUSÕES}

Em princípio, a instauração de um sistema de seguro depósito deve trazer maior estabilidade ao sistema financeiro ao criar um desincentivo a corridas por retiradas de depósitos das instituições financeiras. Contudo, o seguro depósito pode, paradoxalmente, terminar reduzindo a estabilidade do sistema financeiro se induzir ao problema de risco moral. Ou seja, a impossibilidade do fundo gestor do seguro depósito de monitorar perfeitamente as ações das instituições financeiras somada aos interesses conflitantes das partes pode induzir as instituições financeiras a se exporem mais ao risco do que o nível preconizado pelo fundo gestor do seguro depósito.

Evidenciada a ausência de consenso na literatura sobre o efeito da instauração de sistemas de seguro depósito sobre o nível de exposição ao risco de instituições financeiras, notadamente as cooperativas de crédito, o presente estudo buscou evidências empíricas sobre esse tópico no Brasil. Em particular, obtiveram-se evidências empíricas sobre o efeito da instauração do Fundo Garantidor, a partir de outubro de 2005, do Sistema das Cooperativas de Crédito do Brasil (Sicoob) sobre o grau de exposição ao risco de suas cooperativas filiadas. Para tanto, foram utilizados painéis de dados construídos para uma amostra de $61,43 \%$ das cooperativas filiadas ao Sicoob entre janeiro de 2000 e junho de 2008 . Ademais, foi utilizado o índice de Basileia que é um Índice de Adequação do Capital (recomendado por Karels and McClatchey (1999) e Clair (1984)) como proxy para o grau de exposição ao risco das cooperativas.

As principais conclusões obtidas indicaram que, controlando-se para efeitos fixos das cooperativas, ceteris paribus: cooperativas brasileiras de crédito de tamanho médio tendem a se expor menos ao risco que as de tamanho grande e essas menos do que as de tamanho pequeno; quanto maior é o tempo de existência (idade em anos) da cooperativa, maior é o seu nível de exposição ao risco; cooperativas dominadas por membros tomadores de recursos se expõem menos ao risco que os outros tipos de cooperativas de crédito (neutras ou dominadas por membros aplicadores/poupadores de recursos); e quanto maior for o valor da taxa de crescimento dos ativos de uma cooperativas maior será o seu nível esperado de exposição ao risco.

Ainda detectou-se: uma tendência de piora do indicador de adequação de capital (índice de Basileia) no período de transição até a instauração do FGS; uma redução do nível geral de exposição ao risco das 
cooperativas de crédito após a instauração do FGS; e, finalmente, uma tendência de aumento no nível de exposição ao risco das cooperativas de crédito após a instauração do FGS, o que nos levou a concluir que a instauração do FGS induziu as cooperativas de crédito brasileiras ao problema de risco moral. Note-se que esse resultado demonstra a necessidade de se reformular o FGS com vistas a transformá-lo em um mecanismo que traga estabilidade ao setor de cooperativas de crédito e, por conseguinte, a todo o sistema financeiro brasileiro.

\section{BIBLIOGRAPHY}

Alston, L. J., Grove, W. A., \& Wheelock, D. C. (1994). Why do banks fail? Evidence from the 1920's. Explorations in Economic History, 31:409-431.

Baltagi, B. H. (2005). Econometric Analysis of Panel Data. John Wiley \& Sons, New York, 3rd edition.

Baltagi, B. H. \& Wu, P. X. (1999). Unequally spaced panel data regressions with AR(1) disturbances. Econometric Theory, 15:814-823.

BANCO CENTRAL DO BRASIL (2006). Comitê da Basileia para supervisão bancária. Disponível em: http://www.bcb.gov.br/fis/supervisao/docs/CorePrinciplesTraducao2006.pdf. Data de acesso: $17 / 10 / 2010$.

Black, H. \& Dugger, R. H. (1981). Credit unions: Growth, competition and regulatory problems. Journal of Finance, 36:529-538.

Brewer III, E. (1995). The impact of deposit insurance on S\&L shareholders' risk/return trade-offs. Journal of Financial Services Research, 9:65-90.

Brewer III, E. \& Mondschean, T. H. (1994). An empirical test of the incentive effects of deposit insurance. Journal of Money, Credit and Banking, 26:146-164.

Bryant, J. (1980). A model of reserves, bank runs and deposit insurance. Journal of Banking and Finance, 4:335-344.

Carr, J., Mathewson, F., \& Quigley, N. (1995). Stability in the absence of deposit insurance: The Canadian banking system, 1890-1966. Journal of Money, Credit and Banking, 27:1137-1158.

Chan, Y.-S., Greenbaum, S. I., \& Thakor, A. V. (1992). Is fairly priced deposit insurance possible? Journal of Finance, 47:227-245.

Clair, R. T. (1984). Deposit insurance, moral hazard and credit unions. Federal Reserve Bank of Dallas Economic Review, July:1-12.

Davidson, R. \& MacKinnon, J. G. (1993). Estimation and Inference in Econometrics. Oxford University Press, New York.

Demirgüç-Kunt, A. \& Detragiache, E. (2002). Does deposit insurance increase banking system stability? An empirical investigation. Journal of Monetary Economics, 49:1373-1406.

Demirgüç-Kunt, A. \& Kane, E. J. (2002). Deposit insurance around the globe: Where does it work? Journal of Economic Perspectives, 16:175-195.

Diamond, D. W. \& Dybvig, P. H. (1983). Bank runs, deposit insurance and liquidity. Journal of Political Economy, 91:401-419. 
Dreyfus, J.-F., Saunders, A., \& Allen, L. (1994). Deposit insurance and regulatory forbearance: Are caps on insured deposits optimal? Journal of Money, Credit and Banking, 26:412-437.

FGC (2011). Fundo Garantidor de Créditos. Limite de Cobertura. http://www.fgc.org.br/?ci_ menu=20\&conteudo=1. Data de acesso: 09/02/2011.

FGS (2011). Fundo Garantidor do Sicoob. http://www . sicoob.com.br/site/conteudo/sistema_ sicoob/sicoob_fundo_garantidor/. Data de acesso: 09/02/2011.

Fischer, K. P. \& Fournier, E. M. (2002). Does corporate governance matter in deposit insurance? DI and moral hazard in joint stock and mutual financial intermediaries. CIRPÉE Working Paper 02/06, Faculte des Sciences de l'Administration. Universite Laval, Quebec, Canada. http://ssrn. com/abstract= 350660. Data de acesso: 26/06/2007.

Gropp, R. \& Vesala, J. (2004). Deposit insurance, moral hazard and market monitoring. Working paper series 4, European Central Bank. http: //www. ecb. int. Data de acesso: 15/11/2007.

Grossman, R. S. (1992). Deposit insurance, regulation and moral hazard in the thrift industry: Evidence from the 1930's. The American Economic Review, 82:800-821.

Hannafin, K. M. G. \& McKillop, D. G. (2007). Deposit insurance and credit unions: An international perspective. Journal of Financial Regulation and Compliance, 15:1358-1988.

Hansen, C. B. (2007). Generalized least squares inference in panel and multilevel models with serial correlation and fixed effects. Journal of Econometrics, 140:670-694.

Hassan, K. M., Karels, G. V., \& Peterson, M. O. (1994). Deposit insurance, market discipline and off-balance sheet banking risk of large U.S. commercial banks. Journal of Banking and Finance, 18:575-593.

Judge, G. G., Griffiths, W., Hill, R. C., \& Lutkepohl, H. (1985). The Theory and practice of Econometrics. Wiley, New York, 2nd edition.

Kane, E. J. \& Hendershott, R. (1996). The federal deposit insurance fund that didn't put a bite on U.S. taxpayers. Journal of Banking and Finance, 20:1305-1327.

Kareken, J. H. \& Wallace, N. (1978). Deposit insurance and bank regulation: A partial-equilibrium exposition. Journal of Business, 51:413-438.

Karels, G. V. \& McClatchey, C. A. (1999). Deposit insurance and risk-taking behavior in the credit union industry. Journal of Banking and Finance, 23:105-134.

Keating, B. P. (1979). Prescriptions for efficiency in nonprofit firms. Applied Economics, 11:321-332.

Keeley, M. C. (1990). Deposit insurance, risk and market power in banking. The American Economic Review, 80:1183-1200.

Kopcke, R. W. (2000). Deposit insurance, capital requirements and financial stability. Working Paper 00-3, Federal Reserve Bank of Boston, address. DOI: 10.2139/ssrn.240005.

Milhaupt, C. J. (1999). Japan's experience with deposit insurance and failing banks: Implications for financial regulatory design? Monetary and Economic Studies, 17:21-46.

Patin, R. P. \& McNiel, D. W. (1991). Benefit imbalances among credit union member groups: Evidence of borrower-dominated, saver-dominated and neutral behavior? Applied Economics, 23:769-780. 
Pyle, D. H. (1984). Deregulation and deposit insurance reform. Economic Review 2, Federal Reserve Bank of San Francisco.

Sargent, T. (2010). Interview with Thomas Sargent. The Region, 24:28-39. http: //www.minneapolisfed.org/pubs/region/10-09/region_sept2010.pdf. Data de acesso: $16 / 02 / 2012$.

SICOOB (2006). Números do Sicoob. http://www. sicoob.com.br/site/conteudo/sistema_ sicoob/numeros/. Data de acesso: 13/01/2012.

SICOOB (2012). Manual de regulação institucional: Fundo garantidor do Sicoob. Technical report, Sistema de Cooperativas de Crédito do Brasil.

Soares, M. M. \& de Melo Sobrinho, A. D. (2007). Microfinanças: O papel do Banco Central do Brasil e a importância do cooperativismo de crédito. Technical report, Banco Central do Brasil, Brasília.

Weber, W. E. (2010). Bank liability insurance schemes before 1865. Research department working paper, Federal Reserve Bank of Minneapolis. http://www . minneapolisf ed. org/research/WP/WP679. pdf. Data de acesso: 16/02/2012.

Wheelock, D. C. (1992). Deposit insurance and bank failures: New evidence from the 1920's. Economic Inquiry, 30:530-543.

Wooldridge, J. M. (2002). Econometric Analysis of Cross Section and Panel Data. MIT Press, Cambridge, MA. 